\title{
EVALUATION OF COMFORT FOR PASSENGERS OF RAILWAY VEHICLES
}

The passenger's complex sensation felt during the application of oscillations and/or inertia forces, via the whole-body transmission is defined and evaluated with the help of comfort indexes such as a mean comfort; mean permanent sensation evaluated according to the measurement procedures for the indexes, and comfort on curve transition, discomfort due to a perceived curve entry or reverse transmission, or comfort on discrete events - discomfort, due to a perceived transient oscillation on a straight track, curves and curve transitions. In the text the authors deal with mean comfort evaluation and its qualification with the help of the Comfort Indexes.

\section{Introduction}

The comfort of passengers in a vehicle is influenced by a number of different factors, for example temperature, noise, vibration etc. The paper considers only that part of the comfort influenced by dynamic behaviour of the vehicle. This part of the comfort is described as Ride Comfort or as Comfort. The European standard summarises the relevant works taking into account the effects on ride comfort for passengers from the vibration exposure measured on the car body floor (the simplified method for Mean Comfort evaluation), taking into account the vibration exposure measured on the interfaces (the complete method for evaluation) and taking into account the effects on Ride Comfort for passengers of discrete events (Comfort Discrete Events) and running on curve transitions (Comfort on Curve Transitions).

\section{Ride comfort}

The ride comfort for passengers, or ride comfort is the complex sensation produced on the passenger by car-frame movements of the vehicle transmitted to the whole body through the interfaces.

The sensation is classified as:

- average sensation: based on the vibration applied on a long-time basis (at least some minutes),

- instantaneous sensation: a sudden modification of the average sensation, due to a short basis event (change of the mean lateral acceleration value, roll movement at significant speed, lateral jerk with possible oscillation).

Both the first and the second type of sensation are taken into account in the Mean Comfort evaluation. The second type of sensation is taken into account in the Comfort on Curve Transitions and in Comfort of Discrete Events.
The quantification of Ride Comfort for passengers is performed through simulation computations $[2,4,6,7]$ or trough indirect measurements, i.e. measuring and post-processing the relevant parameters (accelerations and angular velocity, they were measured in the car-body).

\section{Input parameters}

The quantification of Ride Comfort for passengers is performed through indirect measurements, i.e. measuring and post-processing the relevant parameters (accelerations and angular velocity, they were measured in the carbody). Other types of tests and evaluation, such as a direct test based on the direct assessment of the perceptions of tested passengers, and combined tests including both direct and indirect tests are possible as well, but they are not quantified in [1]. The indirect measurements are classified as simplified or complete if the measurements are taken respectively on relevant points of the carbody floor, or also on the interfaces.

When travelling, the passengers' bodies are influenced by vibration due to dynamical movement of a vehicle.

Passengers are people travelling in a vehicle, without specific activities related to the transport.

\section{Ride comfort for passenger evaluation}

Comfort is the complex sensation produced on the passenger during the application of oscillations and/or inertia forces, via the whole-body transmission caused by vehicle - frame movements. It is defined and measured through comfort indexes as:

- Mean comfort: a mean feeling, continuously adjusted, as evaluated through a measurement following the procedures for comfort index $N_{M V}$ and indexes $N_{V A}$ and $N_{V D}$.

\footnotetext{
* Juraj Gerlici, Tomas Lack, Zuzana Ondrova

Faculty of Mechanical Engineering. University of Zilina, Slovakia, E-mail: juraj.gerlici@fstroj.uniza.sk, tomas.lack@fstroj.uniza.sk, zuzana.ondrova@fstroj.uniza.sk.
} 


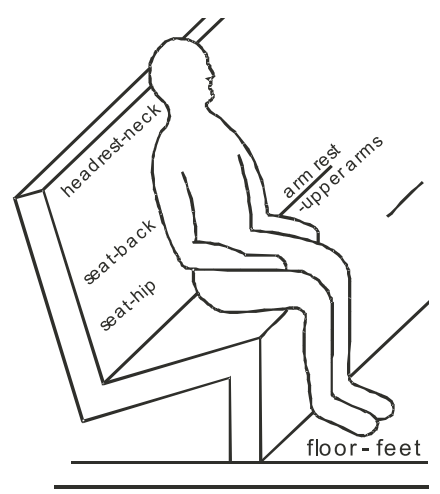

Fig. 1 Interfaces

- Comfort on Curve Transition: discomfort, due to a perceived curve entry or reverse transition, quantified by the recommended procedure indicated as comfort index $P_{C T}$.

- Comfort on Discrete Events: discomfort, due to a perceived transient oscillation on a straight track, curves and curve transitions, qualified by the recommended procedure indicated as comfort index $P_{D E}$

The contact area is compounded from the contact parts between the carbody and the passenger with the function of sustaining and guiding the passenger and of transmitting the weight of the same passenger to the carbody itself; In the standing position (floor-feet), in the seated position (headrest - neck, arm rest - upper arm, seat - hip, seat - back, floor - feet), Whole-body transmission: this is an action transmitted to the whole body through the interfaces.

\section{Indirect measurements/tests features:}

This is a measurement or test or part of tests based on measurement and post-processing of the relevant parameters (acceleration and roll speed measured in the carbody).

Complete measurements are composed of measurements at the positions in accordance to $[1,5,8]$ :

- measurements on interfaces,

- measurements on carbody floor, near to the seat.

Simplified measurements: composed of measurements on the carbody floor at the pre-defined positions.

Two methods are available for the assessment of the passenger perception of Mean Comfort:

- A simplified method based on measurement of acceleration on the floor $\left(N_{M V}\right)$.

- A complete method based on measurement of acceleration at the interface between the passengers and the vehicle $\left(N_{V A}\right.$ and $\left.N_{V D}\right)$.

The complete method is more highly correlated with the passenger's perception of comfort than the simplified method. For a general assessment of the ride comfort of a railway vehicle, the simplified method shall be used. For a full assessment of the ride comfort of vehicles (with a view to the passenger's perception of comfort), it is recommended that the complete method is used where needed.

The simplified method of the Mean Comfort assessment can be performed through the following procedures:

- oscillation measurement,

- results of measured data evaluation,

- list of requested track characteristics for vehicles,

- test protocol form.

To find out effective values of weighted accelerations the registered signals must be elaborated with the help of the following methods: analogous, hybrid (analogous in connection with digital) or digital. In order to take into account the different degrees of sensitivity displayed by different individuals as a function of frequency, weighting curves have been established for vertical and horizontal acceleration signals. These curves are defined in tables $[1,5]$. The curves were determined for sinusoidal vibrations; they are considered valid for broad-band stationary vibrations. Although each individual has his own weighting curves, the curves selected are optimum curves for assessing mean vibration comfort.

\section{Statistical analysis technique is based on the following principle:}

- In order to take into account the fluctuating aspect of the vibrations, vibration comfort as perceived by the passenger depends on the extreme values of the weighted rms values.

- The rms-level of vibration is therefore determined over a period of $5 \mathrm{~s}$ in each direction and at each interface.

- This $5 \mathrm{~s}$ interval is the best compromise if the lowest frequencies are to be taken into account and the rms values are to be varied over the range required.

- Different types of histogram of the rms weighted values calculated every $5 \mathrm{~s}$ may be constructed and the 95 th quantiles may be determined; these values are needed for the calculation of the comfort index $N_{M V}$.

- The 95th quantile is obtained by cumulating values of the histogram expressed in percent beginning from lower acceleration classes up to the class where that sum becomes equal to $95 \%$ or just higher.

Weighting curves are defined by mathematical analytical formulae. Their purpose is to modify the final values of numerical elaboration of measured data as to emphasize crucial information which we want to achieve from the measured signal and at the same time to suppress non-essential information for the final value. Coefficients (see Tab. 1) that modify sensitivity of the final evaluation on input measurements according to the type (direction) of acquired accelerations have an important influence on their course.

The coefficients in Tab.1 are utilized in the equations from 1 to 4 . The values are stated on the base of the norm [1] 


\begin{tabular}{|c|c|c|c|c|c|c|c|c|c|c|c|}
\hline & \multicolumn{9}{|c|}{ Weighting frequency range } & \multicolumn{10}{c|}{ Weighting curve parameters } \\
\cline { 2 - 29 } & $\begin{array}{c}f_{1} \\
{[\mathrm{~Hz}]}\end{array}$ & $\begin{array}{c}f_{2} \\
{[\mathrm{~Hz}]}\end{array}$ & $Q_{1}$ & $\begin{array}{c}f_{3} \\
{[\mathrm{~Hz}]}\end{array}$ & $\begin{array}{c}f_{4} \\
{[\mathrm{~Hz}]}\end{array}$ & $\begin{array}{c}f_{5} \\
{[\mathrm{~Hz}]}\end{array}$ & $\begin{array}{c}f_{6} \\
{[\mathrm{~Hz}]}\end{array}$ & $Q_{2}$ & $Q_{3}$ & $Q_{4}$ & $K$ \\
\hline$W_{a}$ & 0.4 & 100 & 0.71 & - & - & - & - & - & - & - & - \\
\hline$W_{b}$ & & & & 16 & 16 & 2.5 & 4 & 0.63 & 0.8 & 0.8 & 0.4 \\
\hline$W_{c}$ & & & & 8 & 8 & - & - & 0.63 & - & - & 1.0 \\
\hline$W_{d}$ & & & & 2 & 2 & - & - & 0.63 & - & - & 1.0 \\
\hline
\end{tabular}

$$
H_{A}(s)=\frac{s^{2} \cdot 4 \cdot \pi^{2} \cdot f^{2}}{\left(s^{2}+\frac{2 \cdot \pi \cdot f_{1}}{Q_{1}} \cdot s+4 \pi^{2} \cdot f_{1}^{2}\right) \cdot\left(s^{2}+\frac{2 \cdot \pi \cdot f_{2}}{Q_{1}} \cdot s+4 \pi^{2} \cdot f_{2}^{2}\right)}
$$

$H_{A}(s)$ - weighting curve $W_{a}$ specification, where $s=i(2 \cdot \pi \cdot f)$, $f=$ frequency in $\mathrm{Hz}$.

$H_{B}(s)$ - transition function of weighting filter $W_{b}$ for vertical direction course

$$
H_{B}(s)=\frac{\left(s+2 \pi f_{3}\right) \cdot\left(s^{2}+\frac{2 \cdot \pi \cdot f_{5}}{Q_{3}} \cdot s+4 \cdot \pi^{2} \cdot f_{5}^{2}\right)}{\left(s^{2}+\frac{2 \cdot \pi \cdot f_{4}}{Q_{2}} \cdot s+4 \cdot \pi^{2} \cdot f_{4}^{2}\right) \cdot\left(s^{2}+\frac{2 \cdot \pi \cdot f_{6}}{Q_{4}} \cdot s+4 \cdot \pi^{2} \cdot f_{6}^{2}\right)} \cdot \frac{2 \cdot \pi \cdot K \cdot f_{4}^{2} \cdot f_{6}^{2}}{f_{3} \cdot f_{5}^{2}}
$$

$H_{B}(s)$ - transition function of weighting filter $W_{d}$ for horizontal direction course

Each interval has in time strictly determined its begin $T_{1}$ and the end $T_{2}$.

$$
H_{D}(s)=\frac{\left(s+2 \pi f_{3}\right)}{\left(s^{2}+\frac{2 \cdot \pi \cdot f_{4}}{Q_{2}} \cdot s+4 \cdot \pi^{2} \cdot f_{4}^{2}\right)} \cdot \frac{2 \cdot \pi \cdot K \cdot f_{4}^{2}}{f_{3}}
$$

The course expression $H_{C}(s)$ - transition function of weighting filter $W_{c}$ for the back - rest.

$$
H_{C}(s)=\frac{\left(s+2 \pi f_{3}\right)}{\left(s^{2}+\frac{2 \cdot \pi \cdot f_{4}}{Q_{2}} \cdot s+4 \cdot \pi^{2} \cdot f_{4}^{2}\right)} \cdot \frac{2 \cdot \pi \cdot K \cdot f_{4}^{2}}{f_{3}}
$$

In this way we stated a number of data blocks. On the base of sampling frequency and time of 5 seconds we determine a number

It has the same analytical expression as $H_{D}(s)$ - transition function of weighting filter $W_{d}$ for horizontal direction. At computation they differ in the coefficient value $f_{3}$ and $f_{4}$.

\section{Ride comfort computation}

There are measured accelerations in the directions of separate coordinate axe $a_{x}, a_{y}, a_{z}[3,5,9]$. There is given a measured frequency of $f_{n}$. On the base of the frequency we state a number of samples which we scan within the time interval of 5 seconds. At the scan frequency of $200 \mathrm{~Hz}$ we acquire 1000 samples in five seconds. cecond - time interval we divide the complete time of scanning (acquisition of samples) into 5 - second - time intervals following each other.

$$
\text { a }
$$

of scans which should be present in the given interval. For a further numerical elaboration it is necessary that this value be a multiple of two. In the case that it is not the above mentioned multiple we substitute it by the nearest higher value which is the multiple of two.

We do the Fast Fourier Transformation (FFT) for a file of data in each time interval defined by $T_{1}$ and $T_{2}$.

We do the computation $C A W$ for the frequency range from $0.4 \mathrm{~Hz}$ to $80 \mathrm{~Hz}$.

We apply the weighting filter $w$ in dependence on the type of evaluation (floor, standing, seated). 


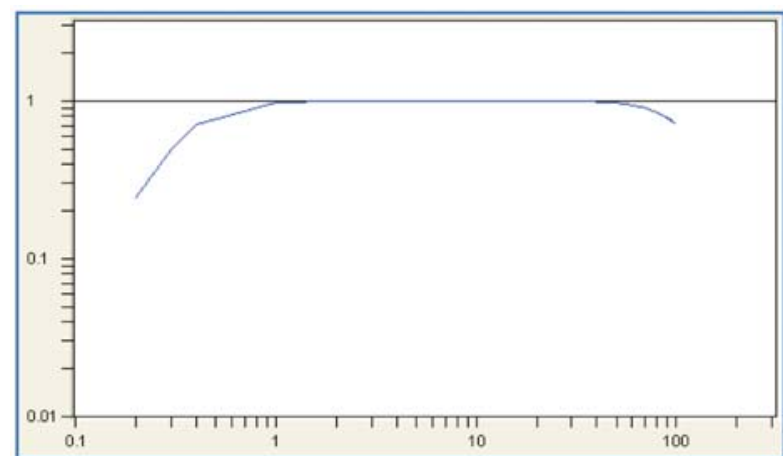

Fig. 2 Graph of $H_{A}(s)$ - weighting curve course
Floor: $N_{M V}$

$$
\begin{aligned}
& N_{M V}=6 \cdot \sqrt{a W x_{95}^{2}+a W y_{95}^{2}+a W z_{95}^{2}}= \\
& =6 \cdot \sqrt{\left(a_{X P 95}^{W_{a b}}\right)^{2}+\left(a_{Y P 95}^{W_{a d}}\right)^{2}+\left(a_{Z P 95}^{W_{a b}}\right)^{2}}
\end{aligned}
$$

a standing position: $N_{V D}$

$$
\begin{aligned}
& N_{V D}=3 \cdot \sqrt{16 \cdot a W x_{50}^{2}+4 \cdot a W y_{50}^{2}+a W z_{50}^{2}}+5 \cdot a W y_{95}^{2}= \\
& =3 \cdot \sqrt{16 \cdot\left(a_{X P 50}^{W_{a b}}\right)^{2}+4 \cdot\left(a_{Y P 50}^{W_{a d}}\right)^{2}+\left(a_{Z P 50}^{W_{a b}}\right)^{2}}+5 \cdot\left(a_{Y P 95}^{W_{a d}}\right)(7)
\end{aligned}
$$

Similar expressions can be written for a sitting person comfort index evaluation.

$$
C A W=\sqrt{\frac{\sum_{f=0.4 H z}^{80 H z}\left|C \cdot C^{*}\right|}{2}}=\sqrt{\frac{\sum_{f=0.4 H z}^{80 H z}|w \cdot[\mathrm{Re}, \mathrm{Im}] \times[\mathrm{Re},(-\mathrm{Im})]|}{2}}
$$

where

$C=w \cdot(\operatorname{Re}, \operatorname{Im}) \quad C^{*}=w \cdot(\operatorname{Re},-\operatorname{Im})$

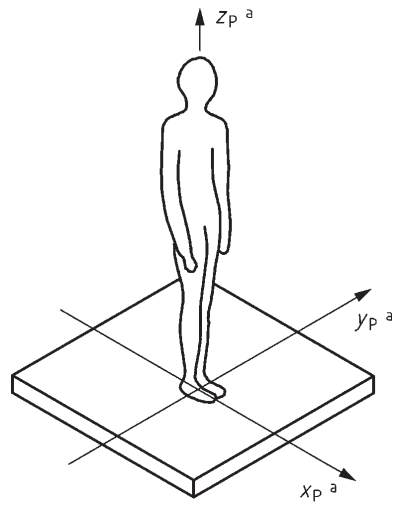

Fig. 3 Standing position

In a statistical way we evaluate acceleration values modified by the weighting function in corresponding directions and we determine summating functions in histograms.

From the histograms for the values of $95 \%$ and $50 \%$ of the summating function we find out the acceleration values $a W x_{95}$, $a W y_{50}, a W y_{95}, a W z_{50}, a W z_{95}$.

$$
\begin{aligned}
& W x=W_{d} \cdot W_{a}=W_{a d}, \quad W y=W_{d} \cdot W_{a}=W_{a d} \\
& W z=W_{b} \cdot W_{a}=W_{a b}, \quad W d=W_{c} \cdot W_{a}=W_{a c}
\end{aligned}
$$

$a W x_{50}=$ acceleration value in the direction $x$ multiplied by the weighting function $W x$ at $50 \%$ quantile of the summating function.

We state the final values of ride comfort indexes for passengers from the following formulae.
For a sitting position: $N_{V A}$

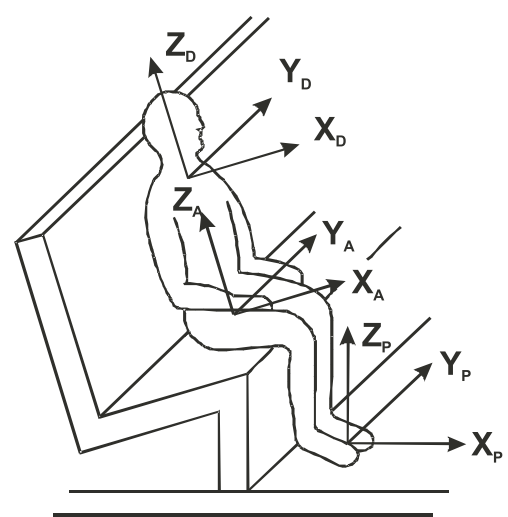

Fig. 4 A sitting person

$N_{V A}=4 \cdot a W z_{95}+\sqrt{2 \cdot a W x_{95}^{2}+a W y_{95}^{2}}+4 \cdot W d_{95}^{2}$

The other expression

$N_{V A}=4 \cdot\left(a_{Z P 95}^{W_{a b}}\right)+2 \cdot \sqrt{\left(a_{Y A 95}^{W_{a d}}\right)^{2}+\left(a_{Z A 95}^{W_{a b}}\right)^{2}}+$

$+4 \cdot\left(a_{X D 95}^{W_{a c}}\right)$.

\section{Conclusion}

The evaluation of ride comfort for passengers is an extremely current issue. A subjective feeling of comfort when travelling is often the decisive criterion which influences the traveller - passenger when choosing a means of transport. Except for economic influences which arise from preferring or refusing some of transport means in the frame of transport system of a country or region, the level of transport system development has a direct 


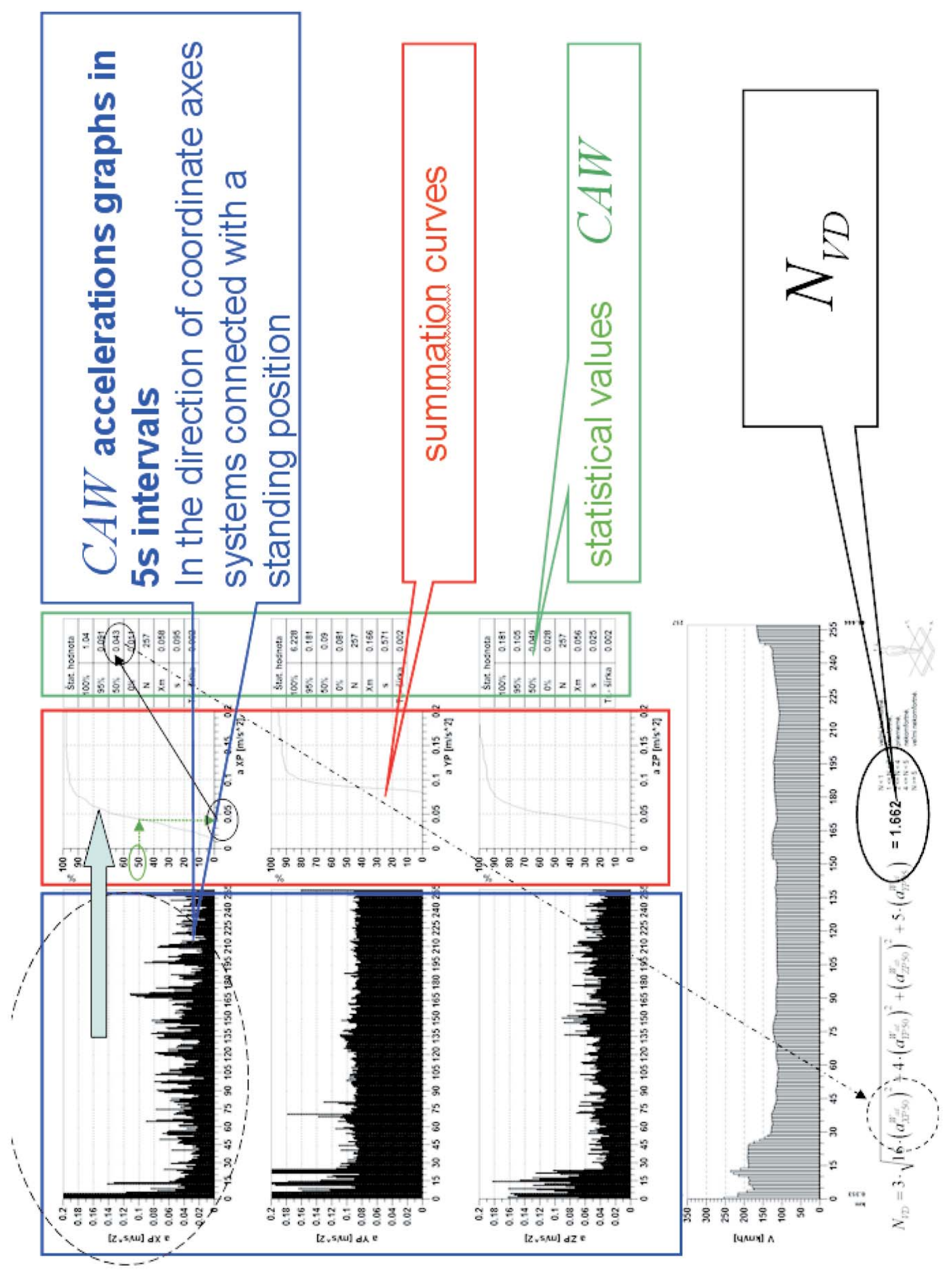

Fig. 5 The acceleration spectrum in the coordinates axe directions is depicted 
binding to regional development, social, economic and environmental relations $[10,11,12]$.

The aim of comfort evaluation procedures by the indirect method (acceleration measurements) and by statistical evaluation is to achieve a concrete number, a comfort index which, when doing the analysis, takes into consideration the quality of the couple vehicle/track and it is not influenced by subjective feelings of individual passengers.

Vehicle properties from the point of view of comfort have an essential influence on the reliability of vehicle parts which are placed on the vehicle -frame.

The coordinate systems are connected (Fig. 5) with a standing person. The right graphs column are histograms with acceleration summating functions, the tables on the right side of the figure contain statistical values of measurements and assessments.

There is a new comfort index evaluation scale in validity

Tab. 2

$N<1.5 \quad$ Very comfortable $\quad 3.5 \leq N<4.5$ Uncomfortable

$1.5 \leq N<2.5$ Comfortable $\quad \mathrm{N} \geq 4.5 \quad$ Very uncomfortable

$2.5 \leq N<3.5$ Medium
The intervals of the comfort indexes values state the comfort classification. They are stated on the base of leaflets. The values specifying the intervals are renewed wen comparing them to he signal values 1999 . The renewed values have been valid since the year of 2006

\section{Acknowledgement}

The work was supported by the Scientific Grant Agency of the Ministry of Education of the Slovak Republic and the Slovak Academy of Sciences in the project No. 1/3169/06 "Properties Research of Rail Vehicles in Movement with Emphasis on the Solution of a Wheel and Rail Contact at the Wheelset Rolling in the Rail via Computer Simulation", in the project No. 1/2116/05: "Interdisciplinary Solution of Modern Rail Transport Means by Usage of Virtual Models and Experimental Methods" and in the project No. 1/4119/07: "Investigation of a dynamical properties of a vehicle“.

\section{References}

[1] ENV 12299: 1999E Railway Applications - Ride Comfort for Passengers - Measurement and Evaluation, European Prestandard, February 1999.

[2] GERLICI, J., LACK, T.: Methods for Vehicle Vibration Analysis in Time Domain. In: Prace naukowe Politechniki Warszawskiej. Z. 63, Transport, 2007. Pp. 71-81. Publishing House of the Warsaw University of Technology. ISSN 1230-9265, Warszawa 2007.

[3] GERLICI, J., LACK, T.: Survey of Ride Comfort for Passengers (in Slovak) In: Acta Mechanica Slovaca, Košice 4-B/2006, pp. 155-162, Optimization of Mechanical Systems, Vol. 10, ISSN 1335 - 2393, Kosice 2006.

[4] GERLICI, J., LACK, T.: An Analysis of Bumpers and Springs Parameters Influence on the Ride Comfort, (in Slovak). In: Dynamics of Rigid and Deformable Bodies. Proceedings of V. international conference. ISBN 978-80-7044-914-1. Pp. 39-48. Univerzita J. E. Purkyne v Usti nad Labem. Usti nad Labem, 2007.

[5] LACK, T.: The Dynamic Properties Analysis of Vehicles from the Point of View of Ride Comfort, (in Slovak). Habilitation Work, pp. 176, Faculty of Mechanical Engineering University of Zilina, 2007.

[6] LACK, T., GERLICI, J.: Vehicles Dynamical Properties Analysis from the Point of View of Comfort for Passengers. Archives of Transport. Vol. 19, issue 1-2, pp. 91-110. ISSN 8066-9546. Warszawa 2007.

[7] LACK, T., GERLICI, J.: The Programme System DELTA Exploitation for Numerical Analysis Performances, (in Slovak). In: 18-th. International Conference "Current Problems in Rail Vehicles - PRORAIL 2007" Proceedings of lectures, Part II. pp. 11-22, EDIS, ISBN 978-80-89276-07-3, Zilina 2007.

[8] LACK, T., GERLICI, J., HLAVNA, V.: Evaluation of Ride Comfort for Passengers, pp. 9-13, Horizonty dopravy, ISSN 1210-0978, 5/2006, Special Edition, Transport Research Institute, Zilina 2006.

[9] LACK, T., GERLICI, J., HLAVNA, V.: The Vehicle Comfort, Case study, Maintenance and Reliability 2006, ISSN 1507-2711, Nr 4(32)/2006, pp. 89-91, Polskie Naukowo-Techniczne Towarysztwo Eksploatacyjne Warszawa, 2006.

[10] ONDROVA, Z., GERLICI, J., LACK, T.: Comfort for Passengers of Railway Vehicle Analysis. In: Proc. of international conference "TRANSCOM 2007", ISBN 978-80-8070-696-8, Section 7, pp. 205-210, EDIS - Publishing house of University of Zilina 2007.

[11] ONDROVA, Z., GERLICI, J., LACK, T.: Comfort for Passengers of Railway Vehicles, (in Slovak). In: Dynamics of Rigid and Deformable Bodies. Proceedings of V. international conference. ISBN 978-80-7044-914-1. pp. 155-164. Univerzita J. E. Purkyne v Usti nad Labem. Usti nad Labem 2007.

[12] ONDROVA, Z., LACK, T., GERLICI, J.: The Ride Comfort for Passengers of a Rail Vehicle, (in Slovak). In: 18-th. International Conference "Current Problems in Rail Vehicles - PRORAIL 2007" Proceedings of lectures, Part II. pp. 127-131, EDIS, ISBN 978-8089276-07-3, Zilina 2007. 